\title{
Ouary Malek (1916 - 2001) : Écrivain et collecteur de la tradition orale kabyle
}

Daniela Merolla et Dahbia Abrous

\section{OpenEdition}

1 Journals

Édition électronique

URL : https://journals.openedition.org/encyclopedieberbere/2856

DOI : $10.4000 /$ encyclopedieberbere.2856

ISSN : 2262-7197

Éditeur

Peeters Publishers

\section{Édition imprimée}

Date de publication : 2 juin 2013

Pagination : 5958-5965

ISBN : 978-2-7584-0194-0

ISSN : 1015-7344

Référence électronique

Daniela Merolla et Dahbia Abrous, « Ouary Malek (1916 - 2001) : Écrivain et collecteur de la tradition orale kabyle », Encyclopédie berbère [En ligne], 36 | 2013, document 042, mis en ligne le 12 mars 2021 , consulté le 17 février 2022. URL : http://journals.openedition.org/encyclopedieberbere/2856 ; DOI : https://doi.org/10.4000/encyclopedieberbere.2856

Ce document a été généré automatiquement le 17 février 2022.

(c) Tous droits réservés 


\title{
Ouary Malek (1916 - 2001) : Écrivain et collecteur de la tradition orale kabyle
}

\author{
Daniela Merolla et Dahbia Abrous
}

\section{NOTE DE L'ÉDITEUR}

[Cette notice reprend et actualise celle parue en 1981 dans Hommes et femmes de Kabylie, sous la signature de D. Merolla et D. Abrous ; cf. Bibl.]

1 Ecrivain de langue française, collecteur de la tradition orale kabyle, Malek Ouary est né le 27 janvier 1916, dans une famille de Kabyles chrétiens de Ighil-Ali (tribu des AïtAbbas), village que l'autobiographie de Fadhma Amrouche* a rendu célèbre. Il est décédé le 21 décembre 2001 et est enterré à Argelès-Gazost (Hautes-Pyrénnées, France) où il résidait depuis de nombreuses années.

2 Il fait ses études primaires à l'école communale d'Ighil Ali et chez les Pères Blancs, puis continue ses études secondaires et supérieures à Alger. Il débute dans l'enseignement mais il est mobilisé durant la guerre 1939-1945.

3 A sa démobilisation, il entreprend une carrière de journaliste, collaborant à plusieurs périodiques et produisant des émissions littéraires à Radio-Alger d'abord, puis à l'ORTF à Paris. En 1970, il a été chargé de conférences à l'Université de la Sorbonne nouvelle.

4 Son activité journalistique a contribué à faire connaître le patrimoine culturel kabyle : danse, musique, chants, poèmes et contes. Il a commencé à recueillir les productions orales kabyles dans son village, puis par des enquêtes, dans toute la Kabylie et dans l'émigration kabyle en France. La direction de Radio-Alger décidait en 1955 de faire éditer les vingt reportages que Malek Ouary avait réalisés (en 1953) sur les travailleurs algériens en France : Par les chemins d'émigration. Ils avaient été diffusés sur Radio-Alger en 1954. Ces reportages sont précédés d'une fort intéressante anthologie de chants 
kabyles sur l'émigration : Le collier d'épreuves. Ils révèlent les peines et les souffrances, les espoirs aussi, tant de ceux qui partent que des familles demeurées au village.

La production littéraire de Malek Ouary a obtenu la faveur de la critique et du public en 1956 lors de la publication de son premier roman, Le grain dans la meule. Pour continuer son activité de journaliste pendant la guerre d'indépendance, Malek Ouary a émigré à Paris où il a travaillé à l'ORTF. Marié en France, il y a poursuivi sa carrière de journaliste et d'écrivain, en publiant une collecte des poèmes kabyles, Poèmes et chants de Kabylie (1974), et son deuxième roman, La montagne aux chacals (1981). Pendant sa retraite, il a terminé son troisième roman, La robe kabyle de Baya (2000) et il avait commencé à écrire un essai sur son village d'Ighil-Ali durant la période d'activité missionnaire des Pères Blancs.

$\mathrm{Au}$ coeur de l'activité littéraire et journalistique de Malek Ouary se trouve donc son intérêt passionné pour la langue et la littérature kabyles qu'il a (re-)découvertes après la «rupture intégrale ", lorsque, étudiant à Alger, il a été sevré de sa culture et de sa langue par l'exclusivisme culturel du système scolaire français de la période coloniale.

« Mon entrée à l'école a revêtu pour moi un caractère singulier : on m'y envoyait en quelque sorte pour y désapprendre ma langue afin de m'initier à une autre » (Poèmes et chants de Kabylie, 1974, p. 13).

Il mentionne la grande impression, «l'illumination », suscitée en lui par la lecture de Chants berbères de Kabylie (1939); ce recueil de J. Amrouche lui fit prendre la décision durable de travailler de toutes ses forces, en utilisant la culture française acquise, à la sauvegarde et à la diffusion de la culture kabyle et berbère. Son expérience individuelle et la situation socio-historique lui faisaient craindre, comme à jean Amrouche, la disparition ${ }^{1}$ du patrimoine culturel kabyle. Son activité se concentre alors sur la collecte de documents, souvent uniques, comme l'enregistrement des chorales féminines du pays des Aït-Abbas dans les années 1950, la traduction de poèmes et de contes, l'enquête sur la narration littéraire dans la société kabyle.

Dans son écriture littéraire, on retrouve l'interaction de tous ces éléments. Par exemple, le noyau du récit dans Le grain dans la meule, ce lien tragique entre amitié, honneur, et mort, est l'élaboration d'un événement narré en tant que fait authentique par un compatriote de l'auteur et initialement recueilli pour une transmission radiophonique. Le manuscrit du roman montre également l'interaction et le passage entre différents registres linguistiques, fruit de l'expérience de l'auteur en tant que journaliste et traducteur de poèmes kabyles. Malek Ouary explique ${ }^{2}$ que les dialogues sont modelés par l'usage quotidien du kabyle, et que des parties entières des discussions à la tajmast (Djema ${ }^{*}$ ) ont été reprises à partir des conversations enregistrées lors de ses enquêtes journalistiques en Kabylie. L'écriture ainsi élaborée donne un ton aulique et élevé au roman et le pose au-delà de l'écriture française "classique", trait qui - et ce n'est pas un hasard - a fait l'objet des recensions diverses, bien que le roman ait été apprécié par la critique de l'époque (Blazat 1956, Pèlerin 1956, Vergnolle 1956).

9 Une partie de la critique littéraire récente (post-coloniale) présente les romans en français des auteurs kabyles (Malek Ouary, Mouloud Feraoun* et Mouloud Mammeri*), comme expression d'une période dite « ethnographique » de la littérature algérienne ${ }^{3}$. Cette caractérisation tient à la fois au cadre temporel choisi : des romans situés dans la période pré-coloniale ou qui ne rompent pas complètement avec l'histoire coloniale ; au cadre dit "régional": le choix d'un espace narratif kabyle et de personnages 
kabyles; et à la question du lectorat: le public français auquel ces romans s'adressaient. Bien que de façon moins explicite que pour Feraoun et Mammeri, on a fait une telle lecture des romans de Malek Ouary (Achour 1990, p. 164-65, 233).

Sur la question du lectorat, on doit admettre qu'effectivement les romans de Malek Ouary s'adressaient à un public principalement "français": l'auteur lui-même le confirme, en expliquant qu'à l'époque où il était tout imprégné de culture française, il partageait l'idée que toutes les valeurs lui avaient exclusivement été apportées par l'École, qui tendait à la francisation des élèves. Ce n'est qu'à la fin de ses études qu'il a pris conscience que "tout lui venait de l'extérieur» et qu'il devait reconsidérer personnellement les choses apprises et surtout l'apport de sa propre culture. Cet aspect rejoint celui du cadre temporel dans Le grain dans la meule. Le fait de s'adresser à un lectorat français et le fait de situer le récit dans la période pré-coloniale, correspondent ainsi à ce moment de la réflexion de l'auteur sur l'enseignement reçu, et à la nécessité de faire connaître aux "autres" pour "reconnaître" lui-même la réalité kabyle : c'est donc un moment marquant dans le développement individuel et artistique de l'auteur. Ce parcours est semblable à celui des personnages principaux dans ses oeuvres ultérieures, La montagne aux chacals et La robe kabyle de Baya. Dans ces deux romans, sans que l'on puisse les considérer comme des récits purement autobiographiques, les personnages principaux font l'expérience de la séparation du pays et de sa culture et puis se tournent vers leur communauté, en participant à la guerre de libération de l'Algérie.

11 Quant au choix "régional", il est indispensable de rappeler qu'il s'agit d'un mouvement très enraciné dans le milieu intellectuel kabyle, et en Kabylie en général, dans lequel des stratégies différenciées ont été mises en place depuis la fin du XIX ${ }^{\mathrm{e}}$ siècle, avec pour but souvent explicite de remettre en cause la subordination ancienne du kabyle et du berbère par rapport aux autres langues et cultures du Maghreb (cf. Chaker 1989/1998, chap. 2). Le choix d'une écriture centrée sur la langue et l'espace kabyles est, encore aujourd'hui, une des stratégies caractérisant la création littéraire des auteurs de langue kabyle (cf. Merolla 1995, 2006). Pour ce qui concerne l'oeuvre de Malek Ouary, il y a une aspiration vers ce que l'on peut appeler une "identité kabyle plurielle", où plusieurs pôles - le monde de la tradition littéraire orale berbère, mais aussi les mutations induites par le contact avec la France et l'utilisation de la langue française - ont une fonction structurante.

12 L'auteur affirme aussi que son écriture voudrait toucher à l'universel à travers le particulier, étant entendu que l'universel n'est pas l'universalisation des normes littéraires d'une seule culture, mais l'aspiration à toucher les structures du sentir et de la compréhension humaine.

13 «Roman non engagé »", a-t-on dit notamment du Grain dans la meule, comme des premiers romans de $\mathrm{M}$. Mammeri, alors qu'on peut au contraire le (les) considérer comme un acte politique. Conçu et rédigé en grande partie avant la guerre de libération algérienne, en pleine période d'assimilation ou d'intégration française, l'ouvrage montrait la société kabyle avec ses valeurs et sa personnalité cohérentes, avant même l'impact de la colonisation. Le fait que ce peuple ait gardé intact son caractère propre à travers les siècles pouvait tout au moins signifier sa résistance passive et la permanence de son identité. Une autre lecture, sociologique, du roman est donc possible; elle fait découvrir au lecteur et comprendre non seulement le contexte du drame mais encore des aspects de la vie sociale en Kabylie. Ouary dépeint les traditions 
dans leur cadre austère, les coutumes et les mœurs, la vie dans les villages sous le signe de la dignité. Mais la toile de fond de la vie familiale et sociale est dominée par l'honneur*: "Le patrimoine moral tient en un seul mot "l'honneur" ». Si «le grain dans la meule " évoque la loi du talion, ce même grain est aussi l'image sociale et culturelle du blé : là où « le pain et le sel sont partagés [ččan tag ${ }^{\circ}$ ella $d$ lmelh], il y a place pour une communauté de vie basée sur la fraternité ».

Ce roman fait découvrir les valeurs humaines et sociales de la Kabylie ancienne et ce retour aux sources, que d'aucuns ont estimé statique et passéiste, permet au contraire une plongée " dans les entrailles du peuple », comme l'écrivait Frantz Fanon à propos de l'écrivain colonisé.

Malek Ouary appartient à la première génération d'écrivains kabyles qui a produit des oeuvres littéraires et des essais importants, contribuant ainsi à la transmission du patrimoine culturel kabyle et à la formation de la riche tradition littéraire "francophone" dans l'espace littéraire kabyle et dans la littérature algérienne.

\section{Malek Ouary et la culture berbère}

Malek Ouary se rattache donc à la chaîne des écrivains culturalistes kabyles au même titre que Boulifa, Jean et Taos Amrouche, Feraoun, Mammeri... (cf. Chaker 1989/1998, chap. 2). Son anthologie de Chants et poèmes de Kabylie, collectés entre 1948 et 1958, puis transcrits et annotés, est précédée d'une introduction, rédigée en 1971, qui constitue un vibrant hommage à la culture berbère. Dans l'introduction, Malek Ouary répond terme à terme aux arguments invoqués pour nier ou marginaliser la culture berbère.

Cette activité de berbérisant et de défenseur de la culture berbère fut, pour Malek Ouary, l'aboutissement d'un cheminement complexe: il y eut d'abord l'enfance et l'immersion totale dans la culture kabyle, puis un brutal sevrage au moment de l'entrée au collège et enfin une ré appropriation difficile mais tenace. L'enfance de Malek Ouary présente des similitudes avec celle de Jean et Taos Amrouche, issus comme lui du village d'Ighil-Ali, de familles kabyles converties au christianisme. Il est comme eux, héritier de la tradition des Igawawen (At Mangellat) par sa mère ${ }^{5}$ et de celle des At-عabbas par son père. Ce double héritage est représenté, pour le côté maternel, par sa tante Chabha, conteuse intarissable et, pour le côté paternel, par deux personnages : un vieillard Ahmed ou Merzouk qui barra la route aux troupes de Bugeaud et une "Dame Troubadour", Lla Hnouna, poétesse qui se déguisait en homme pour mieux circuler. Tous ces personnages ont initié Malek Ouary, très jeune, à la magie du Verbe et à la richesse de la littérature orale kabyle.

Ce fut l'entrée au collège, à l'âge de treize ans, qui rompit le charme, provoquant un sevrage dont il dira : « aujourd'hui, je souffre toujours de ce sevrage prématuré » (1974, p. 15). Cette période de sevrage, qui dura dix ans, fut celle de la formation intellectuelle (français, latin, grec, arabe) et de l'immersion dans la culture des autres. Cette immersion mena Malek Ouary à une interrogation fondamentale :

"Alors, une chose m'a frappé, tout ce que j'avais acquis comme culture venait de

"chez les autres". N'y aurait-il donc rien de valable chez nous? Cela tournait à

l'angoisse et l'idée que la réponse pût être négative, comme certaines bonnes âmes

le proclamaient bien haut, me peinait, m'humiliait » (1974, p. 16).

S. Chaker a bien souligné (1989/1998, chap. 2 et notice M30b « Mammeri Mouloud », EB XXX, 2010) que pour cette génération d'intellectuels kabyles, l'immersion dans la 
culture des autres, « au lieu d'engendrer la classique «honte de soi » des situation de domination, le reniement de ses origines, a, au contraire, provoqué une brutale prise de conscience de la valeur universelle de la culture dont on était issu ».

Cette angoisse fut donc motrice puisqu'elle provoqua une volonté tenace de réappropriation : outre la réappropriation de la langue, Malek Ouary, comme tous les intellectuels kabyles de son époque, entreprit en autodidacte sa formation de berbérisant par le retour aux classiques : Si Mohand ou Mhand*, Boulifa*, mais aussi Hanoteau, Letourneux, Huygue...

21 Alors que cette réappropriation se poursuivait, il y eut « comme une étincelle qui a tout déclenché » : ce fut la publication de l'ouvrage de Jean Amrouche, Chants berbères de Kabylie (1939) ; cette publication orienta résolument Malek Ouary vers le terrain kabyle et en particulier vers le champ de la littérature orale. «C'est alors, écrit Malek Ouary, qu'est né en moi le dessein d'une quête systématique, méthodique de cet héritage dédaigné, presque oublié déjà » (1974, p. 16).

Cette «quête systématique » fut principalement centrée sur la poésie et la musique : pour la poésie, elle déboucha sur la publication des Poèmes et chants de Kabylie en 1974 ; pour la musique, Malek Ouary a réalisé 22 disques souples de chants individuels, de choeurs... en 1946 pour Radio-Alger qui, après les avoir "passés une fois en illustration » a « tout envoyé au pilon ».

23 Mais la poésie et la musique ne furent pas ses centres d'intérêt exclusifs : Malek Ouary s'intéressa à d'autres aspects de la culture kabyle et notamment à l'architecture. Ses Poèmes et Chants de Kabylie ne représentent qu'une faible partie du matériau collecté durant ces années de travail intensif sur le terrain kabyle.

Un poème collecté et traduit par M. Ouary (2002, p. 210-211)

\begin{tabular}{|l|l|}
\hline & Les oublieux. \\
\hline Fransa yewwin akk' arrac & France qui ravit tous nos jeunes gens \\
\hline Wa s zzeef wa s wulac & L'un par humeur, l'autre pour rien \\
\hline Ma yer tmurt yekfa uwelli & Mais au pays point de retour \\
\hline Wa deg Lille wa deg Paris & L'un à Lille, l'autre à Paris \\
\hline Mi zhan irk'elli & Puisqu'ils y sont tous heureux \\
\hline Men kul-wa s tmeddak ${ }^{\circ}$ elt-is & Chacun avec sa compagne \\
\hline Ihedr-ed yid usu $n$ ccac & Vienne la nuit, lit de lingerie \\
\hline Tasumta d tibbac & Et des seins pour oreiller \\
\hline Sut weksum d afilali & Femmes à la chair douce \\
\hline Sut wemzur d rric ak ${ }^{\circ} b a l$ & Chevelure barbe de maïs \\
\hline$\ldots$ & $\ldots$ \\
\hline
\end{tabular}




\section{Euvres de Malek Ouary}

- Par les chemins d'émigration, reportage précédé du Collier d'épreuves, (chants et poèmes kabyles traduits), Alger, Société Algérienne de Publication, 1955.

- Le grain dans la meule, Paris, Buchet-Chastel, 1956. Rééd. : Paris, Bouchène, 2000.

- «Le mouton de la fête », Dialogues, $\mathrm{n}^{\circ} 3$, juillet-août 1963 (conte).

- Poèmes et chants de Kabylie, Paris, St. Germain-des-Prés, 1972 et 1974. Rééd. bilingue français-berbère : Paris, Bouchène, 2002.

- La montagne aux chacals, Paris, Garnier, 1981. Rééd. : Paris, Bouchène, 2000.

- La robe kabyle de Baya, Paris, Bouchène, 2000.

M. Ouary a également publié de nombreuses études et témoignages sur la société et la culture kabyles dans des revues culturelles "grand public", notamment Algeria (1949, 1950, 1951, 1952, 1955), Forge, Ici-Alger, Soleil, qui étaient publiées à Alger dans les années 1950.

\section{BIBLIOGRAPHIE}

ACHOUR, C. (dir.), Dictionnaire des oeuvres algériennes en langue française, Paris, L'Harmattan, 1990.

ARNAUD J., La littérature maghrébine de langue française, I. Origine et perspectives, Paris, Publisud, 1986 [notamment, p. 100-103].

BLAZAT, J., Le grain dans la meule (recension), Le Figaro, sam. 26 mai, 1956.

CHAKER S., Berbères aujourd'hui..., Paris, L'Harmattan, 1989 ; rééd. revue et augmentée : 1998.

DÉJEUX, J., Dictionnaire des auteurs maghrébins de langue française, Paris, Karthala, 1984.

кнатіві А., Le Roman maghrébin, Paris, Maspero, 1968 [p. 47-49].

меммі A. (dir.), Anthologie des écrivains maghrébins d'expression française, Paris, Présence africaine, $2^{\mathrm{e}}$ édit., 1965, p. 245-257.

MEROLLA D., « Peut-on parler d'un espace littéraire kabyle? », Etudes et Documents Berbères, XII, 1995, p. 5-25.

MEROLLA D., De l'art de la narration en tamazight (berbère). Deux cent ans d'études : état des lieux et perspectives, Paris/Louvain, Peeters, 2006.

MEROLLA D. \& ABRous D., « Ouary Malek », Hommes et femmes de Kabylie, DBK I (S. Chaker, dir.), Aixen-Provence, Edisud, 1981, p. 175-178.

PANTUČEK S., La littérature algérienne moderne, Prague, Institut oriental, 1969.

PELERIN, R., « Un nouveau romancier algérien : Malek Ouary », Cahiers Religieux d'Afrique du Nord, Oct.-Déc. 1956, p. 28-31. 
VERGNOLLE, C., «Le grain dans la meule (recension) », Contacts Littéraires et Sociaux, 15 juin/15

septembre 1956.

\section{NOTES}

1. Cette crainte de la disparition est commune à la plupart des écrivains et personnalités culturelles kabyles de formation française de la première moitié du $\mathrm{XX}^{\mathrm{e}}$ siècle : on la retrouve explicitement formulée chez Jean et Taos Amrouche, chez Mouloud Mammeri (jusqu'aux années 1970)... Elle est certainement exagérée par rapport aux données socioculturelles objectives et s'explique en grande partie par des parcours individuels, et familiaux (pour les Amrouche et Ouary), très particuliers, en rupture plus ou moins marquée avec la société d'origine. On peut même détecter chez beaucoup d'entre eux un syndrome de "dernier des Mohicans ", avec le sentiment fort, mais très subjectif, d'être le dernier maillon d'une chaîne de transmission.

2. Entretien accordé à Daniela Merolla au printemps 1998. Nous sommes grandement redevables à M. et Mme Ouary qui nous ont chaleureusement accueillie et nous ont accordé de longs entretiens pendant notre séjour à Argelès-Gazost.

3. Pour Mammeri, il s'agit de son premier roman, La colline oubliée.

4. Ces critiques sont parfaitement datées et idéologiquement situées, qu'elles émanent des intellectuels du nationalisme algérien dans les années 1950 - particulièrement virulents à l'égard de M. Mammeri -, ou de la critique littéraire postcoloniale. Le paramètre berbère ne faisant pas partie du corpus du nationalisme algérien, l'œuvre de ces auteurs kabyles profondément imprégnés de leurs terroirs a ipso facto été considérée comme illégitime.

5. Entretien accordé à Dahbia Abrous, en juillet 1999 à Argelès-Gazost ; l'essentiel de cette notice a été rédigé à partir de cet entretien.

\section{INDEX}

Mots-clés : Kabylie, Littérature, Personnage 